\title{
Leviatán y el atractor extraño Escohotado, Sokal y la vida editorial
}

\author{
JAVIER IZOUIERDO \\ Departamento de Sociología I. UNED
}

Bajo la ceguera del último reflejo de un arqueológico concepto de libertad, no se repara en la abstracta condición política de tal concepto. $Y$ así, cegados por el histórico resplandor de una mitología pasada... no se acaban de asumir las nuevas formas concretas en que la libertad se hace posible y en que la propia actividad política se ofrece.

(Moya, 1984: 204).

\section{INTRODUCCIÓN}

Este lector debe comenzar dándole sincera y efusivamente las gracias al autor de Caos y orden, Premio Espasa de Ensayo 1999, por haber cargado sobre sus hombros con un problema de clarificación filosófica tan endemoniado. En efecto, el último libro de Antonio Escohotado, puede ser considerado un intento, más o menos megalómano, más o menos feliz, pero en todo caso valeroso e imprescindible, de afrontar el increible desafío de volver, en el inicio del nuevo milenio, sobre los restos, aun incandescentes, de la primitiva razón política de la ciencia occidental, para rescatar lo que de históricamente eficiente queda aun de ella, o bien, como según el autor parece ser el caso, para averiguar qué otra especie de «sobredeterminación ritual de nuestro propio entendimiento científico-tecnológico del mundo» (Moya, 1984: 249) ha venido a ocupar su lugar. Tarea intelectual que otros muchos figurones del planeta ensayístico nacional consideran demasiado pesada o bien siguen dejando para mañana y que uno mismo, sin ser del gremio, considera también demasiado ingrata. 
Previamente a ofrecer otra interpretación crítica más del libro de Escohotado, procesándolo exclusivamente en tanto que materia intelectual, será útil aproximarse a él como hecho social. En este sentido, es imperioso tratar de explicar lo que de inexplicablemente enconado -al menos si se lo compara con cualquier otro contexto de debate público, exceptuando, eso sí, el navajerío parlamentario typical spanish- tiene la querella entre Escohotado y aquellos de sus críticos venidos de la más fría academia cientifista.

\section{¿ERRORES «INFANTILES» O INTRUSISMO PROFESIONAL?}

A lo largo de los últimos doscientos años hemos dirigido todos nuestros esfuerzos a entronizar una superstición tan peligrosa como el animismo de los antiguos: la del Todopoderoso Concepto Aritmomórfico. En la actualidad, se correría el riesgo de ser excomulgado de la moderna Academia si se denunciase con demasiada fuerza esta moderna superstición. La disposición natural de nuestro siglo ha llegado así a ajustarse a uno de los adagios de Platón: "Quién nunca busca números en nada, nunca será buscado en el número de los hombres famosos». (Georgescu-Roegen, 1996 [1971]: 129).

Algunos críticos furibundos del libro (Fernández-Rañada, 2000; Peregrín, 2000) ${ }^{1}$ sostienen por su parte que Caos y Orden, debería ser incluido en el «Indice Sokal» de los libros prohibidos por haber cometido, de forma consecutiva, los dos pecados capitales denunciados por el famoso bromista: tomar el nombre de la ciencia en vano y denunciar sus privilegios culturales. Como la «excomunión científica» dictada por los sacerdotes de la Iglesia de San Sokal me parece excesiva, sostendré por contra que el verdadero «pecado», que sería más propio llamar imprudencia, de Escohotado, en mi opinión, es el de haber calculado mal los riesgos en los que incurre el novato cuando invierte de forma intensiva en la adquisición de capital científico de naturaleza extra-escolar.

En un patrón fenomenológico bien conocido por la sociología política de la ciencia, todo intento «lego» por tomar la palabra en un espacio público monopolizado por el credencialismo experto, corre en realidad un riesgo doble. Por un lado está expuesto a las críticas «por defecto» que, en general a través la indiferencia ( «no he leído el libro»), acusan de chapurrear la jerga científica en un nivel tan bajo que resulta irreconocible, por tanto incomprensible, para el especialista que, en este contexto, afirmará, más o menos sinceramente, no disponer ni de los tiempos, ni de las ganas ni de los medios simbólicos necesarios para comprender o hacerse comprender por el lego. Caerían aquí los casos de tantos desgraciados «aprendices de todo y maestros

1 Algo más comedida en el estilo pero igualmente implacable en su mensaje es la pieza de Teira (2000) que, viene a denunciar como «teologal» la abstracta concepción libertaria de lo político que Escohotado desgrana en la segunda parte de su libro. 
de nada» que levantan la voz cotidianamente -por ejemplo en las secciones de cartas al director de los periódicos- para intentar convencernos de lo fundado de sus sospechas contra los alimentos transgénicos, la excesiva concentración en el sector turístico de nuestra balanza comercial o los efectos cancerígenos de usar el teléfono móvil, sin recibir jamás una réplica, aprobadora o demoledora, a cambio.

En el caso que nos ocupa, sin embargo, la amenaza contra el intruso se cumple bajo la acusación inversa del «exceso», si bien esta vez el desprecio proporcionalmente menor del especialista debe necesariamente travestirse bajo la forma más exigente de un trabajo de denuncia pública (quién se dé por aludido deberá ahora, por ejemplo, tomarse la molestia de redactar unas páginas de recensión crítica). Lo que se suele denunciar entonces por escrito es, verdaderamente, una curiosa variedad de falta intelectual: haber sobrepasado el nivel mínimo de erudición técnica a partir del cual los entendidos te leen con lupa y se muestran tan incisivamente críticos como con sus propios colegas. Intentaré ilustrar esta hipótesis, en primer lugar, con un ejemplo extraido de la literatura sociológica.

En una investigación reciente sobre el funcionamiento de los sistemas de vigilancia sanitaria y medioambiental, Francis Chateauraynaud y Didier Torny (1999) han documentado, mediante el análisis de un vastísimo material empírico sobre affaires científicos y opinión pública, el modo como operan el conjunto de restricciones pragmáticas de tipo cognitivo (fiabilidad del enunciado) y moral (credibilidad del enunciador) que pesan sobre las llamadas «voces de alarma exteriores» para su toma en consideración por las instancias de decisión pública. Uno de los casos más problemáticos en este ámbito son, según los autores del estudio, las alarmas pulsadas por sujetos $u$ organizaciones completamente ajenas al mundo profesional de la medicina o las ciencias de la naturaleza, esto es, «legos» individuales (víctimas de enfermedades, periodistas) o bien colectivos (asociaciones ciudadanas, ONGs). En estos casos, las demostraciones de conocimiento y dominio suficiente del léxico y de los argumentos científico-técnicos relevantes al caso pueden llegar a ser tanto o más peligrosas, para el eventual éxito pragmático de la acción comunicativa intentada, como la ausencia total de referencias técnicas ${ }^{2}$.

Un sencillo experimento mental servirá, creo, para explicar el funcionamiento de este curioso mecanismo pragmático de reducción de la variedad

2 «Una alerta que provenga del exterior de las redes institucionales no recibirá el mismo tipo de tratamiento según si recurre o no al lenguaje del dominio [científico-técnico] y a las categorías corrientemente utilizadas por los expertos. Como mostraremos, un alto nivel de inversión técnica no es siempre favorable a la toma en consideración de la señal de alarma por parte de las instituciones porque siguiere o sobreentiende que los fenómenos o los procesos a los que hace referencia han sido mal percibidos o mal definidos o infravalorados por los expertos oficiales. Encontramos así numerosos ejemplos de voces de alarma que, creyéndose obligados a argumentar técnicamente sus posiciones, provocan una suerte de auto-descalificación de su mensaje: sus textos y sus informes son leídos como resultado de una sobreinterpretación de signos y relaciones». (Chateauraynaud y Torny, 1999: 58). 
empírica, a priori infinita, de actos legítimos de comunicación pública de conocimientos científicos. En el momento en que escribo estas líneas, estoy paralelamente inmerso en la lectura de un libro de divulgación científica sobre temas de economía de la organización industrial, una de las ramas más sofisticadamente matemáticas del análisis microeconómico (seguramente la única disciplina científico-social que puede cumplir con los estándares científicos que manejan los críticos de Escohotado). El texto en cuestión, El dominio de la información. Una guía estratégica para la economía de la red, publicado en 1999, es obra de dos afamados catedráticos de microeconomía aplicada de la igualmente prestigiosa Universidad de Berkeley. El objetivo del libro es divulgar los últimos resultados de la investigación más avanzada en el campo del análisis matemático de la competencia en los mercados de bienes de información, entre un público heterogéneo de ejecutivos empresariales con formación académica, pero intentando también hacerlos accesibles a un espectro social más amplio de lectores educados curiosos de las peculiaridades económicas de las empresas «punto-com». Los autores han de hacer, entonces, un uso más libre literariamente y por tanto técnicamente menos preciso de complejos sistemas de proposiciones matemáticas y verificaciones econométricas, glosando de forma amena y sencilla un corpus considerable de artículos científicos cuya lista encontramos en la bibliografía final.

Como resulta que he leído con anterioridad una buena parte de los artículos científicos originales cuyo material destilan al sentido común los profesores de Berkeley (que son a su vez autores o coautores de una buena cantidad de las referencias académicas citadas), no puedo por menos de sobresaltarme a cada paso por la enorme «ligereza» y el aparente «descuido» con los que son tratados definiciones muy sutiles y pruebas estadísticas muy precisas de conceptos económicos tan «técnicos» como los de precio límite, precio de penetración, coste de búsqueda, señalización creíble, base instalada, externalidad de red o el endemoniado atrapamiento tecnológico subóptimo. Obviamente, dado que sabía que lo que tenía entre las manos era una obra de divulgación científica escrita por dos autoridades en el tema, había decidido desde antes aun de iniciar la lectura que, para poder atender a lo realmente interesante de la obra -las conexiones novedosas que establecen los autores entre los nuevos principios teóricos del análisis económico de la información y la abundante casuística periodística disponible sobre las nuevas estrategias empresariales en el mundo de Internet-, tendría necesariamente que restarle importancia a lo que, caso de haber sido los autores dos economistas indocumentados de la Universidad de Peoria, Ohio, hubieran sido para este lector «ligerezas insoportables» $\mathrm{y}$ «descuidos imperdonables».

Sí, estoy convencido de que si en la librería donde lo compré alguien hubiese cambiado la portada original del libro, substituyéndola por otra donde constaran autores falsos, desconocidos o bien con credenciales sospechosas (pe. «director de marketing» o, peor, «consultor estratégico»), mis actuales cautelas a la hora de ponderar negativamente la información contenida en el libro no hubieran sido las mismas. El calificativo «infantil» habría hecho compañía muchas veces al sustantivo, en sí mismo bastante inocuo, «error». 
$Y$ es que el supuesto «infantilismo» de ciertos autores no es otra cosa que un problema de credenciales: otro nombre para el intrusismo profesional.

El desmedido «nivel de incisividad crítica», impensable dentro del pacífico y civilizado ethos comunicativo de la investigación científica contemporánea, con el que ha sido saludado por «la gente de ciencias» el ensayo de Escohotado, sólo puede explicarse, al estilo canónico de la sociología de la ciencia mertoniana, por el tremendo desfase existente entre el contenido intelectual y el continente social de Caos y orden. Desfase al que sin duda contribuyen, aunque en menor medida de lo que se afirma, los supuestos «errores de bulto" cometidos por el autor al glosar determinadas proposiciones teóricas, modelos matemáticos o resultados experimentales de la investigación científica en el campo de la física (en todo caso, tan numerosos o tan poco numerosos como los contenidos en los libros de divulgación científica escritos por científicos académicamente acreditados).

A mi juicio, la verdadera diferencia aquí la establece la presencia o ausencia de motivaciones prácticas que puedan inducir a los lectores a ponerse a buscar y pararse a contar esa clase de errores que son calificados como «infantiles» precisamente porque pueden ser susceptibles de búsqueda. La improbable presencia de los cuales motivos de «presunción de infantilismo científico» tiene, para uno, su explicación más económica en el innegable dato empírico de que el autor de los mismos no sea licenciado (o profesor) en física o en matemáticas, sino filosofante intelectual mediático $y$, por qué no decirlo, extravagante calavera. Y, puesto que la «caridad interpretativa» es un presupuesto elemental para la lectura científica de textos, científicos o no, y que, por tanto, la mala fe es la hipótesis inicialmente descartada en el análisis sociológico de la comunicación científica, la desmedida indignación moral, traducida en tinta como brutal descalificación y mofa cruel, con la que ha sido saludado el libro de Escohotado por aquellos críticos, sólo se explicaría por la explosiva combinación de un corporativo sentimiento de usurpación profesional que, como era de esperar, condiciona en gran medida el contexto de recepción de toda obra de semejantes características, y un ejercicio oportunista del peer reviewing académico que, entiendo, es más bien el subproducto de la "propensión polémica" bajo la que se expresa, con bastante frecuencia, la estructura competitiva francamente monopolista de nuestro mercado editorial.

Pero al margen de estas consideraciones iniciales sobre las convenciones sociales de la comunicación científica que hacen al caso, mi particular delirio nocturno, que llaman sociología, siempre más fuerte que el placer de la buena lectura, me ha obligado a mí también a sentarme al teclado del ordenador para interponer, en lo que sigue de este breve ensayo, una enmienda a la totalidad contra el argumento fundamental del libro de Escohotado sobre la posible comunión entre un nuevo tipo de orden de la naturaleza y un nuevo tipo de orden de la sociedad. Sostendré, en particular, que la ignorancia -o el olvido fatal- de los datos empíricos que pone a nuestra disposición un cuerpo específico de literatura científica, la historia social de las ciencias experimentales (aunque, a la vista de lo que escriben, no se si los «críticos con ganas» de Escohotado me perdonarán por aplicar aquí tal calificativo), es a mi juicio el 
mayor lastre y, junto con algún que otro olvido flagrante ${ }^{3}$, el único pero intelectual verdaderamente importante que puede impugnar las tesis tan supuestamente «radicales» que Escohotado ha presentado para su discusión en foro público ${ }^{4}$.

\section{LA EXTRAÑ̃ HISTORIA DE LA ATRACCIÓN EXTRAÑ̃}

En el fondo todas nuestras concepciones [científicas] tienen un carácter antropomórfico... No creo que el hombre pueda nunca llegar a elaborar una idea tan asombrosa acerca de cualquier causa o relación que exista para ella un modo mejor de ser expresada que el de concebirla «tan vagamente como a un hombre». (Charles S. Peirce).

Mi primera queja se refiere a la insuficiente consistencia -0 más bien «radicalidad»-histórica de las razones filosoficas esgrimidas por Escohotado a lo largo de los siete primeros capítulos de su libro para hacer de una visión artificiosamente ahistórica del triunfo académico de ciertas teorías matemáticas sobre las restricciones a las que está sometido el movimiento de los cuerpos en razón de la energía que disipa, la contrapartida de un nuevo canon emergente (o más bien profético) de libertad política. La historiografía de las prácticas humanas de modelización teórica y manipulación experimental de la naturaleza, empresa mayor de nuestra civilización científica sólo comparable

${ }^{3}$ Estoy pensando en la casi total ausencia de mención (si exceptuamos la referencia en passant al programa de «complejidad económica» del Instituto de Santa Fe, representados por los trabajos de los economistas Brian Arthur, Alan Kirman y Thomas Sargent que se citan en la p. 81 , y la cita de Jean-Pierre Dupuy sobre la «conjetura de Von Foerster» en la p. 202) en el texto de Escohotado de la literatura investigadora sobre la modelización matemática de fenómenos de fluctuación endógena y patrones emergentes de orden no trivial en sistemas complejos de interacción social. Sin duda el cuerpo científico más relevante sobre el que poder apoyar una categoría filosófica tan arriesgada como la de «atractor pueblo». Y aunque Escohotado parece encontrar más útil para sus propósitos teóricos la exploración metafórica de modelos de autoorganización física como el conocido de las «celdas de convección de Bénard», incluso en alguno de los libros del propio Prigogine se alude brevemente a las investigaciones llevadas a cabo a principios de los 70 por el físico-matemático Paul Allen sobre la formación de patrones estadísticos complejos (estructuras urbanas) en la distribución espacial en los asentamientos humanos (Nicolis y Prigogine, 1987: 318-323). Pero el programa de exploración computacional de las «singularidades» matemáticas del comportamiento dinámico de ciertos modelos reticulares de interacción social masiva, incluye sobre todo viejos conocidos del científico-social, algunos tan viejos como el juego de la segregación vecinal de Schelling (i1963!) o el modelo de umbral de la acción colectiva de Granovetter (1978), ejercicios todavía artesanales de exploración de la complejidad social que destilan ya toda la potencia analítica de las modalidades «débiles» de teorizar el paso de la interacción micro al patrón macro sin presuponer una brecha ontológica entre la cualidad de «ordenado" (determinado, etc.) y la cualidad de «desordenado" (impredecible, etc.).

4 ¿ «Peca» de alguna otra cosa grave Escohotado al escribir un ensayo científico en lenguaje fácilmente comprensible? ¿De querer vender muchos ejemplares de su obra? Pecado venial, sin duda, pero a muchos de los que carecen del don de la escritura parece que tampoco les han sido otorgadas facultades para la indulgencia. 
en importancia con el estudio de las partículas físicas fundamentales o del genoma humano -por poner dos ejemplos de programa investigador de reconocido impacto massmediático- es mérito casi exclusivo de las hermanas pobres de la familia universitaria: las humanidades y las ciencias sociales 5 .

Tal vez a causa de su excesiva "concentración», la historia de la físicamatemática del siglo XX que ofrece Escohotado en los primeros siete capítulos de su libro, aunque plagada de hombres y de nombres, no permite percibir demasiado claramente -o por lo menos no tan claramente como lo haría la especificación de una dimensión analítica autónoma del análisis histórico (historia social, historia cultural, etc.)- aquello que de singular y maravilloso tiene el extraño retrato robot de nuestra condición humana (Hannah Arendt) que se dibuja en el «progreso» de la moderna empresa científica. La misma condición humana, sin ir más lejos, que Ilya Prigogine y Benoît Mandelbrot, dos de los particulares héroes de Escohotado, han puesto todo el empeño, y en muchos casos su propia credibilidad ante los colegas, en devolverle a la historia ( $\mathrm{y}$ a la práctica!) de sus disciplinas.

Como ejemplificación estratégica del curioso efecto analítico que, sobre nuestra concepción de qué sea la naturaleza de lo humano, opera la familiarización con el tipo de datos que producen los historiadores sociales y culturales del conocimiento científico, me permito a continuación una breve incursión, creo que extremadamente pertinente al caso, en una de las varias narraciones históricas posibles que pueden construirse sobre los avatares más recientes de nuestros conceptos de orden natural. Me refiero a la génesis moderna de esa más fundamental y misteriosa de las categorías analíticas de la ciencia actual, la de aleatoriedad, una de cuyas acepciones más conspícuas es justamente esa «atracción topológica extraña» que manejan los matemáticos aplicados a la modelización de sistemas dinámicos disipativos, vulgo «caólogos» ${ }^{6}$.

Las primeras nociones formales de probabilidad «subjetiva» o "grado de creencia» (degree of belief) aparecen ya en los siglos XVII y XVIII, en el contexto de las reflexiones teóricas llevadas a cabo por un grupo disperso de filosofos y matemáticas europeos (Pascal, Leibniz, Huygens, Wilkins, De Witt) sobre dos tipos de problemas psico-jurídicos y económicos: la ponderación del «grado probativo» inherente a las diferentes pruebas o evidencias materiales presentadas ante los tribunales de justicia para dirimir contenciosos

5 En cierto modo, esta afirmación contiene ya implícitamente una respuesta a la siguiente pregunta: ¿por qué será que aquellos practicantes que más se afanan en la defensa de la muralla corporativa que asegura el reconocimiento de sus saberes en la forma de una disciplina académica, suelen ser también, por lo general, unos grandes desconocedores de la historia que antecede a la conversión de su específico modo de preocupación por la verdad en trasnochada vocación religiosa?

6 En otro lugar he presentado otros dos modelos narrativos de las más recientes metamorfosis prácticas de nuestro concepto de orden natural, que prestan atención, respectivamente, a la historia de las tecnologías mecánicas de producción industrial de números (máquinas de computación) y su íntima conexión con las técnicas de intervención ingenieril sobre el entorno basadas en la compresión ( «simulación») algorítmica abstracta de su «complejidad organizativa» específica (Izquierdo, 1999, 1.1.1.-1.1.3.). 
legales, y la calibración del riesgo económico compartido en las empresas comerciales conjuntas (Hacking, 1995, caps. 6 y 10). El concepto clásico de probabilidad «objetiva», frecuentista, surge de la mano de la teoría de la «expectativa moral», cuyo desarrollo se encuentra íntimamente ligado al problema práctico del justo reparto de las ganancias esperadas en juegos de azar truncados, con el que Pascal y Fermat probaron sus habilidades matemáticas (Daston, 1988: 15ss.) Trasladada con posterioridad al contexto de la medición astronómica, la regulariad observada en la expectativa matemática de la ganancia en un juego de azar, se metamorfosea en una pretendidamente universal «ley del error de medida», a la que dieran su conocida forma matemática Pierre Simon de Laplace y Carl Friedrich Gauss, y que describe la distribución de las observaciones efectivas alrededor de un valor verdadero o «media objetiva» (Gigerenzer y otros, 1989: 80-84). La ley astronómica del error de medición «normal» fue exportada luego nuevamente a la esfera de la ciencia de los comportamientos humanos con los trabajos estadísticos del astrónomo belga Adolphe Quetelet sobre «el hombre medio» (Porter, 1986: 41-54; Hacking, 1991, cap. 13). Nuevamente, tras leer un informe del estadístico Sir John Herschel sobre los trabajos de Quetelet, el físico-matemático inglés James Clerk Maxwell traspuso la imagen de un «patrón emergente de orden global» en el seno de una población cuyos elementos individuales exhiben comportamientos aparentemente desordenados, a la esfera de las realidades naturales, en este caso formulando las leyes cinéticas de presión y temperatura que rigen la expansión de un gas confinado en un volumen constante. Los trabajos de Maxwell sobre las leyes estadísticas de la cinética de gases («Una encuesta estadística a los gases» era el título de uno de sus artículos sobre el tema) son el inicio de una de las empresas con mayor proyección de futuro de la física contemporánea: la mecánica estadística (Porter, 1986: 111-126). Desde la mecánica estadística, las leyes estocásticas del comportamiento natural se extenderán posteriormente a la termodinámica, la mecánica cuántica y más allá. Y será justamente en la coyuntura del imperialismo de la física estadística durante las décadas de 1930 y 1940 , cuando un grupo de científicos se desplazará de la física a la economía para crear lo que ahora se conoce como «econometría» (Mirowski, 1989). Simultáneamente, a partir de los años 50, la teoría matemática de probabilidades retornará también a otro de sus lugares de origen, la intersección problemática entre de la psicología experimental de la percepción y la teoría organizacional de la toma de decisiones bajo incertidumbre, con el empleo de la teoría de la inferencia estadística y las pruebas de hipótesis como herramientas de análisis teórico en el programa de la flamante psicología cognitiva. Efectivamente, el paradigma cognitivista de la psicología considera, mutatis mutandis, que la mente funciona como un paquete informático de análisis estadístico (Gigerenzer y otros, 1989: 211ss.)

La cosa tampoco termina aquí. Diversos resultados teóricos alcanzados, durante las décadas de 1960-1970, por un disperso conjunto de literatura matemática sobre el problema de la regulación estadística en sistemas dinámicos deterministas con muchos grados de libertad, formarán la base de nuevos programas de investigación, esta vez de carácter empírico, sobre la caracterización 
paramétrica de fenómenos «espontáneos» de ordenamiento «complejo» que algunos dieron en llamar luego «macroestructuras emergentes lejos del equilibrio». Los primitivos modelos matemáticos de crecimiento estocástico desarrollados para dar cuenta de la distribuciones de frecuencias que describen el uso de las palabras en diversas lenguas naturales, el tamaño de las ciudades en ciertos países industrializados o los beneficios medios de las empresas en determinadas ramas industriales, están así en el origen de uno de los más importantes cambios de paradigma ocurridos en las ciencias físicas durante el siglo XX: la teoría del caos. Como lo demuestra, de forma cristalina, la evolución temporal de la obra del matemático Benoît Mandelbrot, el padre de la llamada geometría «fractal» de la naturaleza, muchos de los conceptos formales que han hecho fortuna en el seno de las nuevas teorías físico-matemáticas de la «dinámica caótica» de los sistemas dinámicos naturales, y en particular el tan disputado sintagma de «atractor extraño", proceden directamente de investigaciones sobre modelos de fluctuación de las cotizaciones bursátiles llevadas a cabo en el ámbito de la econometría financiera, o sobre modelos de generación de cadenas discursivas en el campo de la estadística linguística (Mirowski, 1995; Mandelbrot, 1997).

Penúltimo capítulo de esta historia interminable de la naturalización de las relaciones sociales y la simultánea socialización de las relaciones naturales, la reciente re-importación de los modelos matemáticos de dinámica caótica y organización compleja de la energía física como modelo de procesos económicos de asignación de recursos tan importantes como la concentración geográfica de la producción industrial o las decisiones empresariales de inversión en investigación y desarrollo de productos, ha acabado teniendo un impacto decisivo tanto sobre los principios más sagrados de la teoría económica del bienestar social, como sobre las propias estructuras institucionales en las que la competencia mercantil se substancia históricamente?

7 A propósito de este último avatar de nuestra historia, el prestigioso economista estadounidense -y divulgador científico de éxito- Paul Krugman ha escrito lo siguiente: «La evolución de la economía, de forma comprensible, sigue la línea de la menor resistencia matemática. Nos gustaría explicar el mundo en términos de las fuerzas que sabemos representar en un modelo, no de aquéllas que no sabemos modelizar. En la ciencia económica internacional esto ha conducido, desde los tiempos de Ricardo hasta la década de 1980 , a un énfasis casi exclusivo en la ventaja comparativa, en lugar de prestar atención a los rendimientos crecientes como explicación del comercio. La razón de esto es que la ventaja comparativa podía ser representada utilizando modelos que suponían rendimientos constantes y competencia perfecta, que eran los instrumentos matemáticos que se tenían a mano. La profesión simplemente dejó al margen aquéllos aspectos del comercio internacional que no podían ser representados de este modo." (Krugman, 1992: 10-12). Compárese con la afirmación siguiente, referida a un fenómeno paralelo en la historia del análisis matemático de los procesos físicos, de los inevitables Prigogine y Stengers, tan apreciados por los buscones indisciplinados como Escohotado como sospechosos a ojos de los cancerberos del rigor disciplinar de la ciencia académica: «Cómo entender que de un problema meramente «técnico" - la imposibilidad de definir una función que la evolución de un sistema dinámico haga crecer con el tiempo, como es el caso de la entropía- haya podido nacer esta afirmación de consecuencias casi inconcebibles: que la diferencia entre pasado y futuro no tiene realidad objetiva? ¿Cómo entender la singularidad cultural que ha permitido a la física negar una evidencia tan abrumadora que ninguna cultura la había puesto en cuestión hasta entonces?» (Prigogine y Stengers, 1990: 14). 


\section{LA CIENCIA Y EL LEVIATÁN}

El título que Hobbes da a su obra es altamente significativo: Leviatán es el monstruo bíblico cuyo supremo poder no admite par en la tierra (Job, 41, 25-26); sólo la cólera de Dios puede contra él, simbólica encarnación del poder político de Egipto, opresor y esclavizador del pueblo de Israel, elegido Reino de Dios segün el "pacto» con Abraham y Moisés... Desde el propio sentido simbólico de tal nombre, el Leviatán, en cuanto modelo político del Estado absoluto, es la negación del arquetipo político-religioso del Reino de Dios. (Moya, 1984: 264-265).

Si en la primera parte de su libro Escohotado re-escribe una cierta historia de la física contemporánea desde un punto de vista que a grandes rasgos puede considerarse «exterior», o al menos bastante más alejado de la visión «autóctona» que de ella poseen sus propios protagonistas de lo que recomiendan los cánones metodológicos en el campo de la historia social y cultural de las ciencias, en la segunda se permite el «lujo filosófico» correlativo de alzar el conocimiento de la naturaleza como espejo de la actividad política. Efectivamente, la segunda parte de Caos y orden se centra en los avatares de la libertad política enfrentada día a día a lo que Escohotado gusta llamar «el orden de la orden»-la burocracia legislativo-administrativa del moderno Estado Nacional. Esta segunda historia ha sido contada también muchas veces, ciertamente con mayor y más aburrido trabajo probatorio y aún teórico, no con más belleza (y sólo por la calidad de su escritura Caos y orden pertenece a otra división literaria que en nuestros país pocos pueden jugar). Pero aun a sabiendas de la sincera preocupación politológica del autor para con las radicales novedades políticas de la vida cotidiana contemporánea $-\mathrm{y}$ aun reconociendo el interés de sus interesantes consideraciones al respecto ( $c f$. el capítulo XVII)-, he de confesar que su peculiar narración de las sucesivas idas y venidas históricas del anhelo moderno de liberación política de las sociedades occidentales se me antoja excesivamente afín, en su filosófica abstracción, con la purificada hagiografía de la «liberación energética» de la materia inerte que nos había contado antes.

La justificación epistemológica de los fundamentos filosófico-naturales esgrimidos originalmente por Thomas Hobbes para, a su vez, justificar politológicamente el naciente monopolio estatal sobre la violencia legítima como único remedio consistente contra el desorden civil generalizado, sólo puede entenderse si se conoce la íntima conexión pragmática entre la nueva ciencia del Leviatán y la primera controversia experimental digna de tal nombre que, al objeto de determinar la naturaleza real y las causas verdaderas de ciertos «extraños» fenómenos neumáticos (notablemente, el llamado «espacio de Torricelli»), tuvo lugar en Inglaterra a mediados del siglo XVII. Este el argumento de una interesante obra de investigación historiográfica sobre el origen, no tanto «ritualmente sobredeterminado» ${ }^{8}$ como pragmáticamente convenido

8 «Enfrentarse con el discurso de Leviatán... obliga a volver sobre los últimos fundamentos epistemológicos del lenguaje científico contemporáneo. [...] A la vez que se inventa el lenguaje 
(Wittgenstein), de la divisoria moderna entre Razón Científica y Razón de Estado.

La obra en cuestión - publicada por Princeton University Press en 1985 y, a día de hoy, lamentablemente sin traducción castellana- se titula Leviathan and the Air-Pump: Hobbes, Boyle and the Experimental Life [Leviatán y la bomba de vacío: Hobbes, Boyle y la vida experimental ${ }^{9}$. Sus autores, dos profesores de historia de la ciencia británicos, Steven Shapin de la Universidad de Edimburgo y Simon Schaffer de la Universidad de Cambridge, diseccionan la disputa, indisociablemente experimental y gubernamental, que, en el contexto de la Restauración de la monarquía inglesa, tras la sangrienta guerra civil a la que sucedió la dictadura del Lord Protector Cromwell, enfrentó cara a cara dos concepciones unitarias del mundo: la de Thomas Hobbes, físico-politólogo aferrado a una visión artificialista del orden social para la cual se apoyaba en una concepción estrictamente mecanicista del mundo físico, y la de Robert Boyle, politólogo-físico, inventor de una conocida tecnología de prueba experimental, la bomba de vacío. Boyle es asímismo el patentador de una tecnología literaria que alcanzaría en poco tiempo una dimensión cultural quasi-universal: el régimen moral de enunciación (los marcadores textuales de «buena fe» $\mathrm{y}$ «modestia») que deben emplear aquellas persona que pretenden comunicar a los demás «cuestiones de hecho». Más precisamente, lo que fue «inventado» por Boyle y sancionado por sus colegas de la Royal Society fue ese «juego de lenguaje» ${ }^{10}$ donde se forman una clase especialmente disuasoria de admoniciones ( «Invito a todo aquel que crea que las leyes

analítico de lo que hoy llamamos Ciencia, se produce la representación lógico-conceptual del Estado... para sobredeterminar desde entonces todo el discurso racional de la Sociedad Occidental sobre su propia organización política y sobre toda otra formación política en general.» (Moya, 1984: 249-50).

9 Para algunos comentadores, Leviathan and the Air-Pump, es el gran clásico moderno de la disciplina, pues, sostienen, tiene la virtud de ser la primera investigación que efectivamente establece un principio de «simetría antropológica» entre las ciencias de la naturaleza y las ciencias del hombre: primera investigación que muestra como los hechos científicos y los hechos sociales se construyen mutuamente. «[Shapin y Schaffer] rompen los confines de la historia intelectual y se trasladan del mundo de las opiniones y de los argumentos al mundo de la práctica y de las destrezas. Por primera vez en la literatura de los estudios sobre la ciencia, es a través de los detalles de la práctica de un instrumento que todas las ideas sobre Dios, Rey, Materia, Milagros y Moral, quedan retraducidas y explicadas. Algunos habíamos estudiado ya la práctica de la ciencia, y también otros habían estudiado el contexto religioso, político y cultural de la ciencia, pero nadie hasta entonces había hecho de las dos cosas, una.» (Latour, 1990: 151-152).

10 «En nuestra cultura, decir que el conocimiento es artificial y convencional es tanto como decir que no es al fin y al cabo conocimiento auténtico. Esta disposición general explica el hecho de que aquellos ejercicios académicos aplicados a desvelar y exponer las bases convencionales del conocimiento, como los llevados a cabo por Wittgenstein, son interpretados como otros tantos actos de denuncia o menosprecio. En la vida cotidiana, nosotros mismos quitamos importancia a las aseveraciones de los demás intentando mostrar su naturaleza construida o sus fundamentos convencionales. Tales prácticas tienen sentido dentro de un juego de lenguaje particular. Un juego... en el que, por así decirlo, no es la agencia humana (individual o colectiva) quien responde del conocimiento logrado, sino la realidad misma.» (Shapin y Schaffer, 1985: 150). 
de la física son mercas convenciones sociales a que trate de transgredirlas desde la ventana de mi apartamento. Vivo en el piso número $21 .{ }^{11}$ ) que llamamos «hechos científicos» ${ }^{2}$.

La tesis central que sostienen Shapin y Schaffer es, resumida, la siguiente. Con la resolución final de la ancestral querella de la filosofía natural sobre el modo legítimo de argumentar sobre la existencia del vacío, en la que la primera comunidad científica de pares que conocemos (la flamante Royal Society de Londres) declaró vencedor al régimen de prueba experimental abanderado por Boyle frente a la metodología geométrico-deductiva representada por las posiciones de Hobbes, parece haber quedado definitivamente esbozada la abrupta frontera práctica que separa hoy al conocimiento verdadero sobre las cosas del conocimiento necesario para el bueno gobierno de los humanos. La sentencia final del caso Hobbes-Boyle constaba de dos cláusulas legislativas paralelas que rigen desde entonces, con mayor o menor éxito, la empresa toda de la ciencia occidental. Por un lado, se declaró que las proposiciones que, desde Popper, llamamos «falsables», esto es, aquellas estrictamente respaldadas por datos experimentales, por tanto siempre empíricamente dubitables y teóricamente ambivalentes, son las únicas certezas, reconocidamente débiles, de las que puede proveernos el estudio organizado de un tipo de orden metafísico, el orden de las cosas de la naturaleza, que, en su mayor parte, no ha sido aun modificado por la mano del hombre -pero véase Latour [1999].

El segundo punto de la sentencia del caso Hobbes-Boyle -verdadero precedente legislativo de lo que Bruno Latour ha dado en llamar «Constitución moderna» (Latour, 1990)- es también de sobras conocido (aunque las infinitas situaciones vitales que nos hacen recordar su vigencia no sean, en nuestro entorno académico, todo lo frecuentemente exploradas que algunos quisiéramos): dada su débil potencia normativa, las certezas que produce la ciencia experimental no son admisibles como principio duradero de normalización social. Esta segunda cláusula puede también interpretarse del modo siguiente: quedó también legislado que el único principio asegurador capaz de garantizar

11 Reproducidos aquí textualmente la «advertencia» (o más bien amenaza) incluida en la nota 3 del «final report», publicado originalment en 1996 por la revista Dissent, donde el travieso Alan Sokal discute los resultados finales de su experimentum crucis sobre la debilidad de los dispositivos de protección contra el fraude intelectual de los que dispone la academia internacional de los «estudios culturales» ( $c f$. A. Sokal, «Transgredir las fronteras: un epílogo», reproducido como Apendice C en Sokal y Bricmont, 1999: 283-294, la cita es de la p. 284).

12 «El objetivo de la tecnología literaria de Boyle era asegurar a sus lectores de que el autor del texto era el tipo de persona en cuya palabra podía confiarse. Tuvo por tanto que encontrar los medios para hacer visible en sus textos los atributos aceptables de un hombre de buena fe. Una de las técnicas más características en este sentido era la de reportar experimentos fallidos. Un hombre que es capaz de informar sobre el fracaso de sus experimentos es un hombre cuya objetividad no puede estar distorsionada por sus intereses. El despliegue literario de un cierto tipo de moralidad constituía así una de las técnicas esenciales en la fabricación de una cuestión de hecho. Un hombre cuyas narraciones pudieran ser acreditadas como espejos de la realidad habria de ser un hombre modesto; sus informes deben hacer visible la modestia.» (Shapin y Schaffer, 1985: 65, 69). 
por sí sólo la cientificidad del conocimiento social es la existencia de un sistema efectivo de poder político y no de un método científico, vgr. la aplicación de un «conjunto de reglas para llevar a cabo una investigación».

Por cierto que la ignorancia -o mejor sería decir, el olvido- de esta segunda verdad histórica sobre nuestro mundo, correlativa de la primera, puede ser causa de tremendas meteduras de pata empíricas cuando, quienes se ganan la vida custodiando el primero de ambos dogmas, intentan aventurarse en los dominios del segundo. Algunas tan «sokalescas» como esta:

«Hay casos [de investigación policial] en los que ni el escéptico más recalcitrante pondrá en duda que, en la práctica, se ha encontrado realmente al culpable. Uno puede, en definitiva, tener el arma del crimen, las huellas dactilares, muestras de ADN, documentos, un móvil, etc. [...] Nadie duda de que, por lo menos en algunas investigaciones (las mejores) el resultado obtenido se corresponda con la realidad.» (Sokal y Bricmont, 1999: 70-71).

Una afirmación como ésta implica un desconocimiento flagrante del carácter adversarial del procedimiento legal en nuestras sociedades. ¿Cual es la función que nuestras leyes procedimentales asignan al fiscal sino es la de adoptar un «escepticismo recalcitrante» respecto a los resultados obtenidos por (las mejores) investigaciones policiales? Otro tanto puede decirse del talante, crítico por definición, con el que los abogados de la defensa y de la acusación y, por su puesto, los jueces han de ponderar los resultados de las pruebas periciales que la investigación policial aporta en un juicio -incluidos, por su puesto, los de aquellas más aparentemente científicas, como las pruebas de ADN 13. Más aun: la garantía de un juicio justo sólo puede estar basada en la posibilidad de "poner radicalmente en duda» los resultados de las pericias forenses llevadas a cabo por los expertos al servicio de la policía. Pero el papel subordinado de los datos científicos, bajo la forma de evidencia forense, en el contexto de la investigación judicial, no es sino una de las muestras más evidentes de la impotencia normativa más genérica del conocimiento científico experimentalmente producido. Más allá del ámbito exclusivo de las disputas legales, la capacidad para construir argumentos críticos con el objetivo de desmontar las bases teóricas y metodológicas de los «hechos objetivos» sobre los que sustentamos nuestros juicios de atribución, puede considerarse como una de las competencias cognitivas más notorias del sentido común de la justicia que todos ponemos insensiblemente en práctica en nuestra vida cotidiana. De hecho, sólo así puede explicarse la existencia en nuestras sociedades de desacuerdos duraderos sobre «la realidad de las cosas» de los que son buena muestra, por ejemplo, los litigios interminables que desencadenan las denuncias por negligencia profesional (Chateauraynaud, 1991, parte III).

${ }^{13}$ Como antídoto contra el delirio filosófico de Sokal y Bricmont, recomiendo aquí la lectura del modélico estudio sociográfico de Halfon (1998) sobre los pormenores de la actual controversia en torno a la estandarización científica y la validez jurídica de los resultados de pruebas de identificación de sujetos llevada a cabo mediante el análisis comparativo de muestras de ADN. 
Así pues, desde la feroz cruzada filosófica emprendida por Hobbes contra los demonios gemelos del Vacío Físico y la Guerra Civil hasta los más recientes proyectos modernistas y postmodernistas de codificación de los fundamentos pragmáticos de la acción comunicativa (Habermas) y las estructuras histórico-sociales de posibilidad de la subjetividad individual (Foucault), el terrorífico presupuesto filosófico de la decidibilidad política de la acción social es la segadora universal de la que se sirve el pensamiento filosófico para desbrozar la selva de la vida humana ${ }^{14}$. Pero han sido sobre todo las modernas ciencias sociales, la psicología, la economía, la sociología y la politología, quienes han convertido este máquina intelectual en verdadera «máquina de guerra» (Deleuze), esto es, en el imperativo tecnológico sobre el que asentar la posibilidad práctica de construir una ordenación burocrática duradera de la vida política en las sociedades complejas. Ordenamiento práctico de la conducta, que admite desde la versión «exógena» más simple del autoritarismo nacionalista hasta las versiones «endógenas» más sutiles y meta-estables (Moya, 1984: 245-246) que ofrecen las tecnologías de gobierno a distancia instrumentadas por los regímenes liberales avanzado. Versiones suaves del orden social que los sociólogos más cursis adjetivamos como «auto-organizadas», «reticulares», «complejas» o «globales» (Boltanski y Chiapello, 1999: 208-226) y que Escohotado dice «caóticas».

\section{CONCLUSIÓN}

Considero que las anteriores disgresiones, introducidas para intentar mostrar el espíritu específicamente sociológico, de mi particular lectura de Caos y

14 «Los programas filos6ficos de Hobbes y Boyle estaban ambos igualmente preocupados por el problema del asentimiento y el consentimiento [assent], pero sus soluciones eran radicalmente diferentes. Según la postura de Boyle el asentimiento debía asegurarse mediante la producción de hallazgos experimentales, traducidos como cuestiones de hecho a través del testimonio colectivo... El programa estaba, por tanto, fundado sobre la colectivizacion de la experiencia sensorial individual... Para Boyle el tipo de obligación [compulsion] que tal empresa debería producir en los demás era sólo parcial, pues debía seguir existiendo espacio para discrepar, siendo la tolerancia considerada como elemento esencial para el mantenimiento de esta obligación parcial y liberal... Para Hobbes en cambio la guerra civil era el único resultado posible de cualquier programa de conocimiento que fuese incapaz de asegurar una obligación absoluta... Cualquier solución válida al problema del conocimiento debería ser a la vez una solución al problema del orden social. Y tal solución habría de ser absoluta. De modo que Hobbes optó por ir más allá del individuo, de su poco fiable experiencia sensorial, y de la categoría de creencia individual. ¿Dónde entonces podría, según Hobbes, residir la obligación? Hobbes localizó su solución no en la creencia ni en el testimonio sino en el comportamiento, no en el individuo sino en lo social... La fuerza mediante la cual se logra la sumisión es la fuerza delegada de todos aquellos que entran en la sociedad y viven en ella como seres sociales. La empresa intelectual que demuestra racionalmente esto a todos los hombres posee por tanto un carácter absolutamente obligatorio. Es para la filosofía lo que el Leviatán es para la sociedad. Los hombres pueden entender completamente aquello que ellos mismos han construido... La fuerza de la lógica es la misma que la fuerza mediante la cual el Leviatán garantiza la sumisión: es la fuerza delegada de la sociedad, actuando sobre las capacidades naturales de razonamiento de todos los hombres.» (Shapin y Schaffer, 1985: 152-53). 
orden, son producto, de una actitud declaradamente amistosa hacia su autor, siquiera, como diría un estadístico «amistosa en promedio». Quienes creen que la estadística es un ciencia de las simetrías cuantitativas, pensarán que la fluctuación extrema de toda la crítica anterior no pueda ser ya compensada con un último párrafo de alabanza final. Más, cuando se considera que lo importante de las desviaciones respecto del promedio no es tanto su magnitud como su límite ${ }^{15}$, los promedios sólo pueden entenderse como impresiones cualitativas más bien inefables, y no como exacta y calculable proporción entre cantidades.

Estoy con Escohotado en lo que, a mi juicio, es lo fundamental de su tesis. Por repetirlo otra vez con distinta paráfrasis: la historia del número, ese auténtico «fetiche» que adora el físico-matemático y que teme el humanista, es la historia de los hombres: de los revolucionarios franceses, sí ${ }^{16}$, pero también del inventor del platino iridiado, un metal que hasta ahora no hemos encontrado en estado puro en la naturaleza y que tuvo su patente, y del inventor del microscopio láser empleado para medir la longitud de onda del kripton-86 y la vibración del átomo de cesio con la que contamos el tiempo (Mirowski, 1992). Y de tantos otros de cuyos hallazgos aun no tenemos constancia los legos (para ya la tendremos), que se las siguen ingeniando para involucrarnos a todos cada vez un poquito más en la materialidad de nuestro propio mundo. Y a la vez, fatalmente, para hacer de nuestro mundo algo cada vez más ajeno y más extraño... Si no fuera porque, a pesar de los muchos guardianes del dogma específicamente religioso de la naturaleza no humana (por no decir inhumana) de las verdades científicas sobre la naturaleza, todavía algunos se afanan, nos afanamos, en hacer que la historia de la naturaleza, la historia de las ciencias y la historia de, digamos, los hombres en sociedad, no se olviden entre sí. ¿Quién puede negar que este legítimo, elemental empeño académico sea otra cosa que un «ejercicio responsable de la libertad» en una sociedad plural? Pero a lo peor es este el verdadero pecado cometido por Escohotado...

\section{REFERENCIAS CITADAS}

Boltanski, luc y Eve Chiapello (1999): Le Nouvelle Esprit du capitalisme, París, Gallimard.

Chateauraynaud, Francis (1991): La faute profesionelle. Une sociologie des conflits de responsabilité, París, Métailié.

15 Como supongo que algun parroquiano de la diocesis matemático-estadística habrá que se vea tentado de excomulgarme por tan irreverente uso del lenguaje sagrado de las matemáticas. debo explicar que considero el contexto de uso lingüistico anterior de los tales términos consistente con las agudas observaciones metodológicas de Mandelbrot (1963) sobre la diferencia entre «varianza limitada» y "varianza infinita».

${ }^{16}$ Como es bien sabido, la base del sistema métrico-decimal, el metro, fue decretado en una diez millonésima del meridiano terrestre que pasa por París por un estatuto francés de 6 de abril de 1795 - 18 de germinal del años IIl en el calendario revolucionario ( $c f$. « Un rey, una ley, una pesa y una medida!», en Kula, 1980: 321-380). 
- y DIDIER TORNY (1999): Les sombres precurseurs. Une sociologie pragmatique de l'alerte et du risque, París, Editions de I'EHESS.

Daston, Lorrain J. (1988a): Classical Probability in the Enlightenment, Princeton, Princeton University Press.

Fernández-Rañada (2000): «Del caos postmoderno», Revista de libros, 40: 33-34.

GEORgESCU-RoEgen, Nicholas (1996): La ley de la entropía y el proceso económico [1971], Madrid, Visor-Fundación Argentaria.

Gigerenzer, Gerd; Zeno Swistink, Theodore Porter, Lorraine Daston, John Beatty y Lorenz Krúger (1989): The Empire of Chance. How Probability Change Science and Everyday Life, Cambridge, UK, Cambridge University Press.

HACKING, Ian (1991): La domesticación del azar, Barcelona, Gedisa.

- (1995); El surgimiento de la probabilidad, Barcelona, Gedisa.

Halfon, Saul (1998): «Collecting, Testing and Convincing: Forensic DNA Experts in the Courts", Social Studies of Science, 28: 801-828.

IzQuIERDo, A. Javier (1999): De la fiabilidad, Tesis doctoral inédita, Universidad Complutense.

Krugman, Paul (1992): Geografía y comercio, Barcelona, Antoni Bosch.

Kula, Witold (1980): Las medidas y los hombres, Madrid, Siglo XXI.

LaTour, Bruno (1990): «Postmodern? No, Simply Amodern! Steps Towards an Anthropology of Sciences», Studies in History and Philosophy of Science, 21(1): 145-17.

- (1999): La politique de la nature, París, La Découverte.

Mandelbrot, Benoît (1963): «The Variation of Certain Speculative Prices», Journal of Business, 36 (October) [reproducido en P. Cootner (ed.), The Random Character of Stock Market Prices, Cambridge, MA: MIT Press, 1964: 307-32].

- (1997); "Three Fractal Models in Finance: Discontinuity, Concentration, Risk», Economic Notes by Banca Monti dei Paschi di Siena, 26 (2): 171-212.

MiRowski, Philip (1989): «The Probabilistic Counter-Revolution, or How Stochastic Concepts Came to Neoclassical Economic Theory», Oxford Economic Papers, 41 (1): 217-235.

- (1992): «Looking for Those Natural Numbers: Dimensionless Constants and the Idea of Natural Measurement», Science in Context, 5(1): 165-188.

- (1995): «Mandelbrot's Economics after a Quarter Century», Fractals, 3: 581-600.

MoYa, Carlos (1984); Señas de Leviatán, Madrid, Alianza.

Nicolis, Grégoire e Ilya Prigogine, La estructura de lo complejo, Madrid, Alianza, 1987.

Peregrín Gutiérez, Fernando (2000): «A la atención de los miembros del Premio Espasa de Ensayo 1999», mimeografiado del autor.

Prigogine, Ilya e Isabelle STEngers (1990): Entre el tiempo y la eternidad, Madrid, Alianza.

Shapin, Steven y Simon Schaffer (1985): Leviathan and the Air-Pump. Hobbes, Boyle and the Experimental Life, Princeton, NJ: Princeton University Press.

SoKal, Alan y Eric Bricmont (1999): Imposturas intelectuales, Barcelona, Paidós.

TeIRA, David (2000): «La divina espontaneidad del caos», Anabasis 3, en prensa. 